\title{
THE BEHAVIOUR OF SAPPHIRE UNDER INTENSE TWO-COLOUR EXCITATION BY PICOSECOND LASER
}

\author{
M. Gedvilas, V. Stankevič, and G. Račiukaitis \\ Center for Physical Sciences and Technology, Savanorių 231, 02300 Vilnius, Lithuania \\ Email: g.raciukaitis@ftmc.lt
}

Received 20 May 2021; accepted 21 May 2021

\begin{abstract}
Ultrashort pulse lasers are evidencing their benefits in the processing of transparent materials. Sapphire is one of the most attractive engineering materials today. It is hard and, therefore, difficult to machine mechanically to the required shape. Laser dicing is one of the promising techniques for sapphire separation. Two-pulse two-colour irradiation was applied to initiate free-shape cutting of the material. Two collinear laser beams with wavelengths of 1064 and $355 \mathrm{~nm}$, pulse duration of $10 \mathrm{ps}$ and inter-pulse delay of $0.1 \mathrm{~ns}$ were combined to induce intra-volume modifications (directional cracks) in sapphire for wafer separation. The photon energy of both beams is well below the band gap, and various channels of the multi-photon excitation were involved in the process. Significant enhancement in the modification area was experimentally observed when intensities of focused infrared and ultraviolet beams were within narrow ranges. We discuss the resonant laser-sapphire interaction mechanisms, leading to up to four times higher excitation of the material involving multiple photons and energetic levels of intrinsic defects in the band-gap. The energy level schemes of colour centres involved in two-step multi-photon absorption in sapphire under intensive laser irradiation have been prepared.
\end{abstract}

Keywords: sapphire, picosecond laser, multi-photon excitation, colour centres

PACS: $33.80 . \mathrm{Wz}, 42.50 . \mathrm{Hz}, 42.62 .-\mathrm{b}, 42.62 . \mathrm{Cf}$

\section{Introduction}

Sapphire is a hard and transparent material widely used in industry. Due to superior physical, chemical and optical properties, sapphire is an excellent material for a wide range of applications [1-4], including high-speed integrated circuit chips, lightemitting diode substrates [5, 6], various electronic and mechanical components and optical windows for extreme applications. Sapphire is difficult to machine mechanically because of its high hardness [7]. Many of the potential applications are suspended because of the high cost of sapphire machining.

Laser scribing and ablation are used to separate the sapphire wafer into dice in electronics production [8-11]. However, the laser scribing contaminates the substrate surface. Intra-volume, stealth dicing of sapphire is the most promising laser- based technique [12-15. Directional cleaving of the material with a zero-cut width avoids debris formation.

In the last decade, research activities related to the light-matter interaction utilising the dualwavelength double-pulse laser irradiation have emerged. The significant enhancement of laserinduced plasma ejection has been reported in dual-wavelength double-pulse femtosecond spectroscopy [16]. Laser-induced periodic surface structure (LIPSS) formation on metals [17, 18, semiconductors [19] and dielectrics [20, 21] has been intensively investigated by the two-colour (UV-IR) double-pulse femtosecond laser irradiation. The two-colour double-pulse irradiation has been used for laser-induced damage threshold (LIDT) testing of optical coatings [22-25, and has proved to reduce the damage threshold by $71 \%$ for $\mathrm{Al}_{2} \mathrm{O}_{3}$ coating [26. Better control in 
the energy deposition has been demonstrated during dual-wavelength double-pulse laser machining of dielectrics [27].

Crystalline sapphire $\left(\alpha-\mathrm{Al}_{2} \mathrm{O}_{3}\right)$ is a direct bandgap insulator with $E_{\mathrm{g}}=8.80 \mathrm{eV}$ [29-32], and its transmission spectrum extends from about $145 \mathrm{~nm}$ to $5.2 \mu \mathrm{m}$. In this work, the two-colour double-pulse irradiation was validated for efficient machining of sapphire wafers. Two collinearly combined laser beams with the 1064 and $355 \mathrm{~nm}$ wavelengths, pulse duration of $10 \mathrm{ps}$ and inter-pulse delay of $0.1 \mathrm{~ns}$ were utilised to induce intra-volume modifications (directional cracks) in sapphire [33]. The photon energy of both beams was much below the band-gap, and various channels of the multi-photon excitation were involved in the process. The higher photon energy of UV light at $355 \mathrm{~nm}$ requires only three photons to excite an electron from the valence band to the conduction one. Such a multi-photon process should have a much higher probability than eight-photon absorption (8PA) of the fundamental IR radiation from a laser (at $1064 \mathrm{~nm}$ ).

We expected that the radiation of the third harmonics pulse of low energy would be absorbed nonlinearly and thus would locally excite the charge carriers from the valence to the conduction band. Subsequently, a high-energy firstharmonic laser pulse that reaches the material with some delay could be easily absorbed by electrons in the conduction band, leading to impact ionisation. The absorbed high-energy first-harmonic pulse causes strained stresses in the sapphire. If these stresses exceed the critical limit, cracks are developing. During scanning a laser beam over the sapphire wafer, the sequence of pulses initiate overlapping directional cracks, and a continuous cleavage of the hard material is achieved.

Significant enhancement in the modification area was experimentally observed when intensities of focused infrared and ultraviolet beams were within narrow ranges. Here, we discuss the most likely mechanisms of the resonant laser-sapphire interaction, leading to up to four times higher excitation of sapphire involving multiple photons and energetic levels of intrinsic defects in the band gap. Various models of electron excitation by intense laser light in sapphire were analysed based on previous experience in multi-photon spectroscopy. Energetic models of colour centres involved in two-step multi-photon absorption in sapphire under intense laser irradiation have been prepared.

\section{Experiment}

Stealth dicing of sapphire using two wavelengths was performed to improve the absorption of sapphire using the better-absorbed third harmonic radiation and excitation of valence band electrons into the conduction band. To realise the stealth dicing of sapphire using two wavelengths, a laser optical system for the two-colour double-pulse irradiation with crossed polarisations, as shown in Fig. 11(a), was assembled.

Two different diode-pumped lasers (PL10100, Ekspla) and (Atlantic, Ekspla) with pulse durations of $\tau=10 \mathrm{ps}$ irradiation at a wavelength of $\lambda=1064 \mathrm{~nm}$ were used in the experiments. The first laser provided pulses with energy up to $20 \mu \mathrm{J}$ at a $1 \mathrm{kHz}$ repetition rate. The second laser with the same laser pulse duration and radiation wavelength but higher repetition rate and pulse energy was chosen to upscale the process throughput. The second laser source provided radiation with a pulse energy of $68 \mu \mathrm{J}$ at a repetition rate of $100 \mathrm{kHz}$ with an average power of $6.8 \mathrm{~W}$.

The beam of the picosecond laser was split into two beams using a polarising beam splitting cube. The third harmonics with a wavelength of $355 \mathrm{~nm}$ was generated using the second and third harmonic crystals in one optical path using non-linear crystals. The first harmonics was translated to the workpiece by another optical path. For the second-harmonic generation, an LBO type-I non-linear crystal with a size of $5 \times 5 \times 10 \mathrm{~mm}^{3}$ was used (Eksma Optics). For the third-harmonic generation, an LBO type-II nonlinear crystal with a size of $5 \times 5 \times 8 \mathrm{~mm}^{3}$ was used (Eksma Optics). Both beams were collinearly combined by using a spectrally selective mirror. In the experiments, it was essential to have sufficient overlap of UV and IR laser beams. The combined cross-polarised dual-wavelength double-pulsed beam was focused in the volume of the sapphire wafer by using an aspheric uncoated focusing objective with a focal length of $8.0 \mathrm{~mm}$ and a numerical aperture of 0.50 (A240TM, Thorlabs).

It is easier to focus UV light to a smaller spot. Radiation of different wavelengths focuses at various depths due to chromatic aberrations 

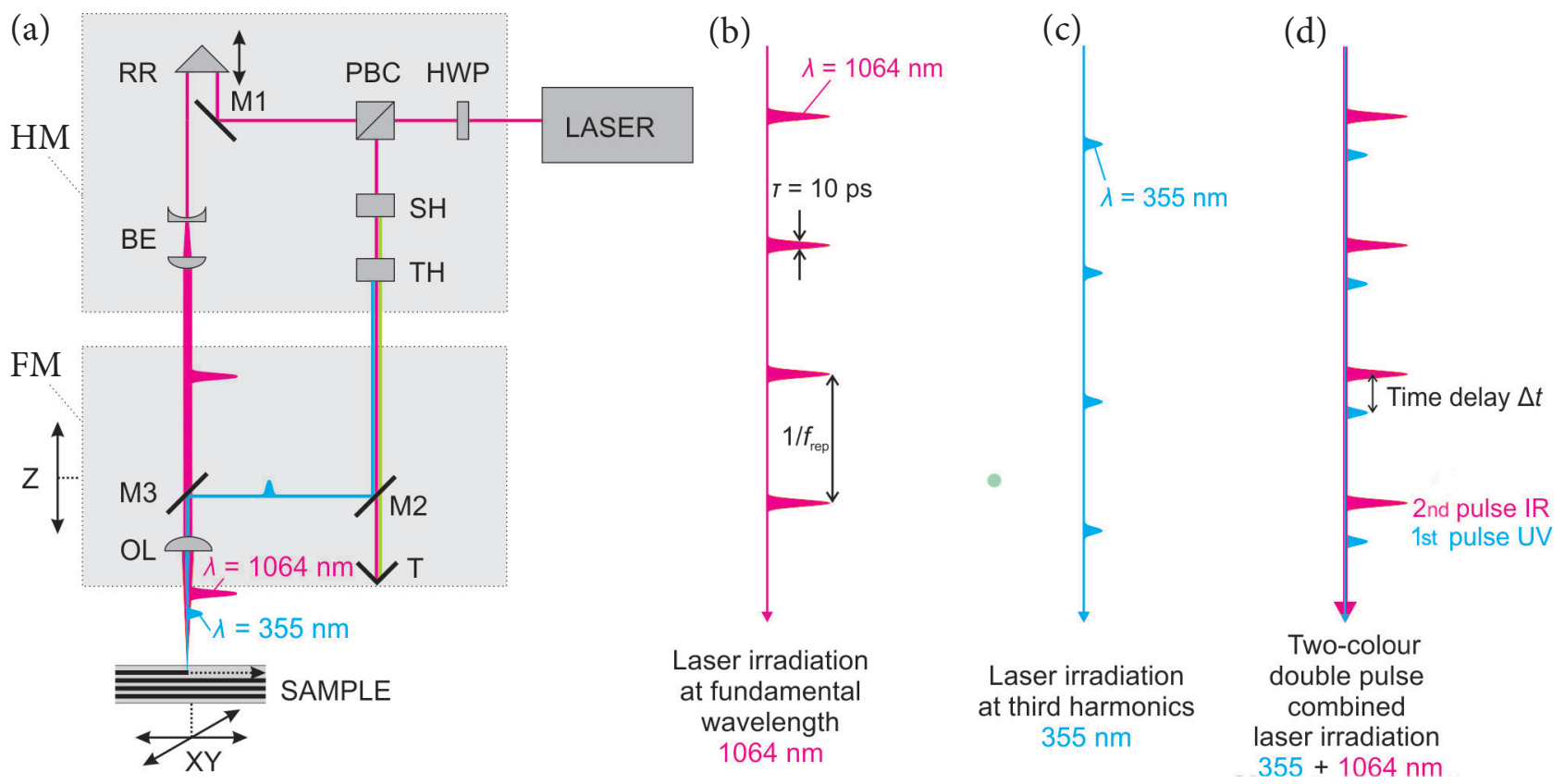

Fig. 1. (a) Experimental set-up for the cross-polarised dual-wavelength double-pulse combined laser irradiation. LASER is the pulsed laser source; HWP is the half-wave plate; PBC is the polarisation beam splitter cube; the delay line with movable retro-reflection prism RR; M1 is a high reflective mirror; $\mathrm{SH}$ and $\mathrm{TH}$ are the second and third harmonic modules; both beams were combined by the spectrally selective mirror M3; M2 is the harmonic beam splitter mirror; OL is the focusing objective; HM is a harmonics generation module; FM is a focusing module with controllable focus position Z; SAMPLE is a sapphire wafer mounted on controllable positioning stage $X Y$. Schematic representation of irradiation regimes: (b) single-pulse IR irradiation at the wavelength of $1064 \mathrm{~nm}$; (c) single-pulse UV irradiation at the wavelength of $355 \mathrm{~nm}$; (d) dual-wavelength double-pulse combined irradiation with the fixed inter-pulse delay of $0.1 \mathrm{~ns}$. Coloured online.

in the focusing optics. Moreover, there is also a difference in the refractive index of sapphire for the light of different used laser wavelengths. A beam expander and additional lens, pre-focusing the 1064 $\mathrm{nm}$ beam, were built in the optical path of the fundamental harmonics to equalise the position and size of the waist in the sapphire as much as possible.

The laser spot sizes of the focused Gaussian beams in the volume of sapphire were measured by the technique described by Liu [34]. For the first laser (laser \#1), the spot size radiuses were $\omega_{0}(355) \approx 3.5 \mu \mathrm{m}$ and $\omega_{0}(1064) \approx 3.3 \mu \mathrm{m}$. The measured spot radiuses for the set-up with laser \#2 were $\omega_{0}(355) \approx 4.4 \mu \mathrm{m}$ and $\omega_{0}(355) \approx 6.0 \mu \mathrm{m}$.

Three different irradiation regimes were examined in the experiments: the single-pulse irradiation by IR or UV laser pulses (Fig. 1 (b, c)) and dual-wavelength double-pulse combined irradiation at a fixed delay between pulses (Fig. 1(d)).

The single-pulse train irradiation was applied using two laser wavelengths: either $1064 \mathrm{~nm}$ (Fig. 1.(b)) or $355 \mathrm{~nm}$ (Fig. 1(c)). In the dualwavelength double-pulse irradiation scheme, the time delay between laser pulses in the doublepulse pairs was controlled by optical delay lines with retro-reflector prisms. It was set to about $\Delta t \approx 100$ ps. The UV pulse arrived at the sample first. The temporal distance between repetitive laser pulses or double-pulse pairs was $1 / f_{\text {rep}}$, where $f_{\text {rep }}$ is the laser repetition rate.

The energy ratio between laser pulses of IR and UV wavelengths was controlled by the orientation angle of the $\lambda / 2$ wavelength plate (HWP) before the polarisation beam splitter. The pulse energy dependences for the fundamental, third and both harmonics combined on the rotation angle of HWP are shown in Fig. 2. Solid lines represent $\sin ^{2}(2 \varphi)$ and $\cos ^{2}(2 \varphi)$ functions and their sum calibrated to the maximal measured value of pulse energies at 0 deg. $(1064 \mathrm{~nm})$ and $45 \mathrm{deg}$. (355 nm) orientation. The total sum of pulse energies of IR and UV pulses decreases by increasing the HWP angle in both cases due to limited conversion efficiency to the third harmonics.

Wafers of the synthetic single crystal sapphire $\left(\alpha-\mathrm{Al}_{2} \mathrm{O}_{3}\right.$, CrystalQ $)$ were used as samples in 

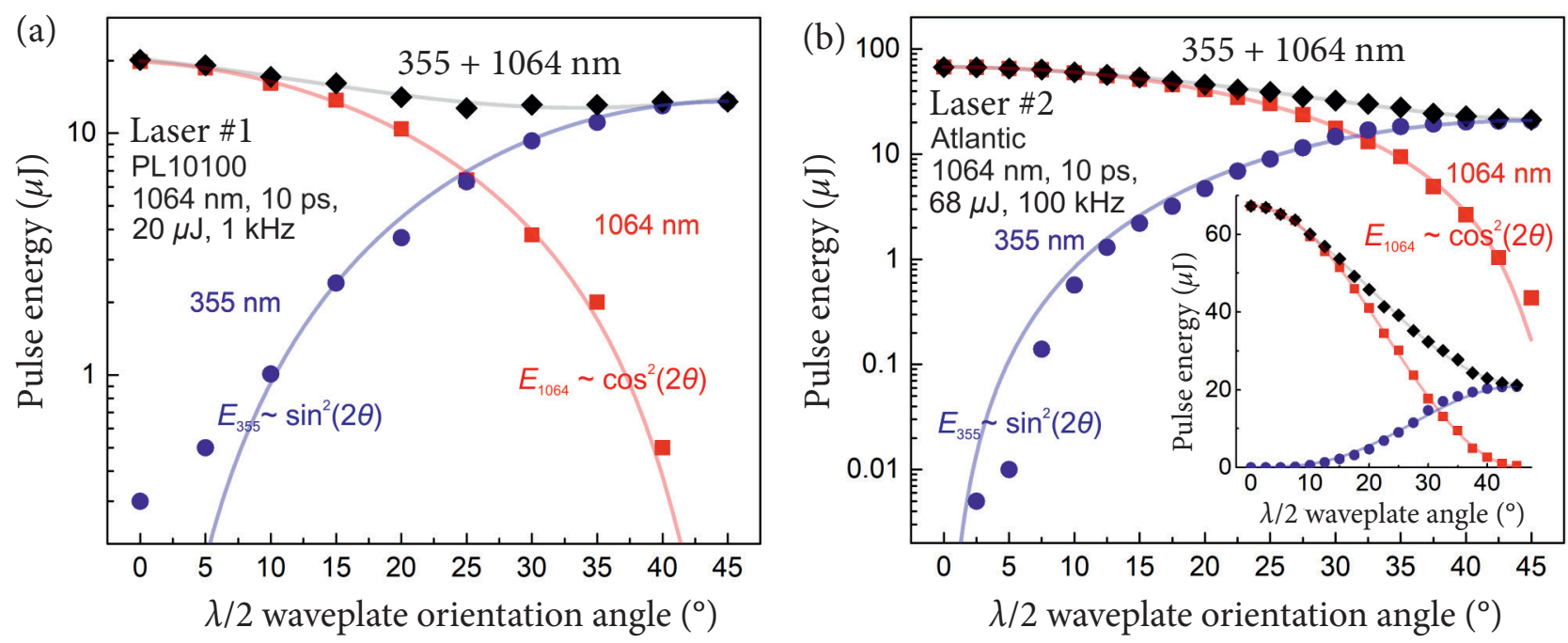

Fig. 2. Pulse energy versus the HWP orientation angle. (a) System with laser \#1. (b) System with laser \#2. Dots are experimental data: (•) IR pulse at the wavelength of $\lambda=1064 \mathrm{~nm} ;(\bullet)$ UV pulse at the wavelength of $\lambda=355 \mathrm{~nm}$; $(\diamond)$ the dual-wavelength double-pulse at the wavelengths of $\lambda=1064 \mathrm{~nm}$ and $\lambda=355 \mathrm{~nm}$. Adapted with permission from reference [33] under CC BY license, Springer Nature. Coloured online.

the experiments. The sapphire wafers with a diameter of $50.8 \mathrm{~mm}$ and thickness of $430 \mu \mathrm{m}$ had an orientation C-plane (0001), off-cut $0.30 \mathrm{deg}$. to $\mathrm{M}$ plane. They were double-sided epi-polished with the top surface roughness of $\mathrm{Ra} \leq 0.3 \mathrm{~nm}$ and bottom surface roughness of $\mathrm{Ra} \leq 0.5 \mathrm{~nm}$. Intravolume modifications of sapphire were investigated using an optical microscope Eclipse LV100, Nikon.

\section{Results}

Sapphire wafers were irradiated by single laser pulses of IR (Fig. 1(b)) or UV (Fig. 1(c)) and the combined double-pulse dual-wavelength irradiation (Fig. 1(d)). The pulse energies of IR and UV beams were varied in opposite directions by changing the orientation angle of the half-wave plate (HWP) (Fig. 2).

The size of intra-volume modifications (cracks) induced by laser irradiation is directly related to the energy absorbed by the material. The optical images of laser-induced transverse intra-volume modifications in the sapphire wafer by a single pulse and the dual-wavelength double-pulse irradiations are given in Fig. 3 .

Experimental data were recorded in single-pulse and double-pulse regimes. Dimensions of internal modification were measured through the optical microscope and plotted as a function of the orientation angle of HWP (Fig. 4). In the single-pulse re- gime, intra-volume modifications appeared in bulk when pulse energy of IR or UV pulses exceeded some particular value.

Considering wide sapphire band-gap $E_{\mathrm{g}}=$ $8.80 \mathrm{eV}$ and multiphoton excitation at high intensity, three photons of UV laser at $355 \mathrm{~nm}$ $(3.493 \mathrm{eV})$ are required to transfer an electron from the valence band to the conduction band (3PA). In the case of IR laser radiation at $1064 \mathrm{~nm}$ $(1.165 \mathrm{eV})$, at least eight photons are needed for inter-band transition (8PA). As excitation processes 3PA and 8PA are independent (data of separate experiments), we can deduct their input to the total modification of sapphire at the joint action of both laser beams ('difference' in Fig. 4). The enhanced modification (intra-volume crack formation) was observed for the double-pulse regime in a pretty narrow range of the HWP rotation angles (5-25 deg). Those experimental results evidence that the absorbed first UV pulse enhanced the absorption of the second IR pulse in the dualwavelength double-pulse irradiation. The delay of $\sim 100$ ps between UV and IR pulses was found to be optimal for enhanced modification of the material [33]. In addition, UV luminescence was observed in the focal area inside the sapphire wafer during laser treatment with focused 10 ps laser pulses (Fig. 5).

The primary purpose of this work was to investigate what excitation mechanism is responsible for 


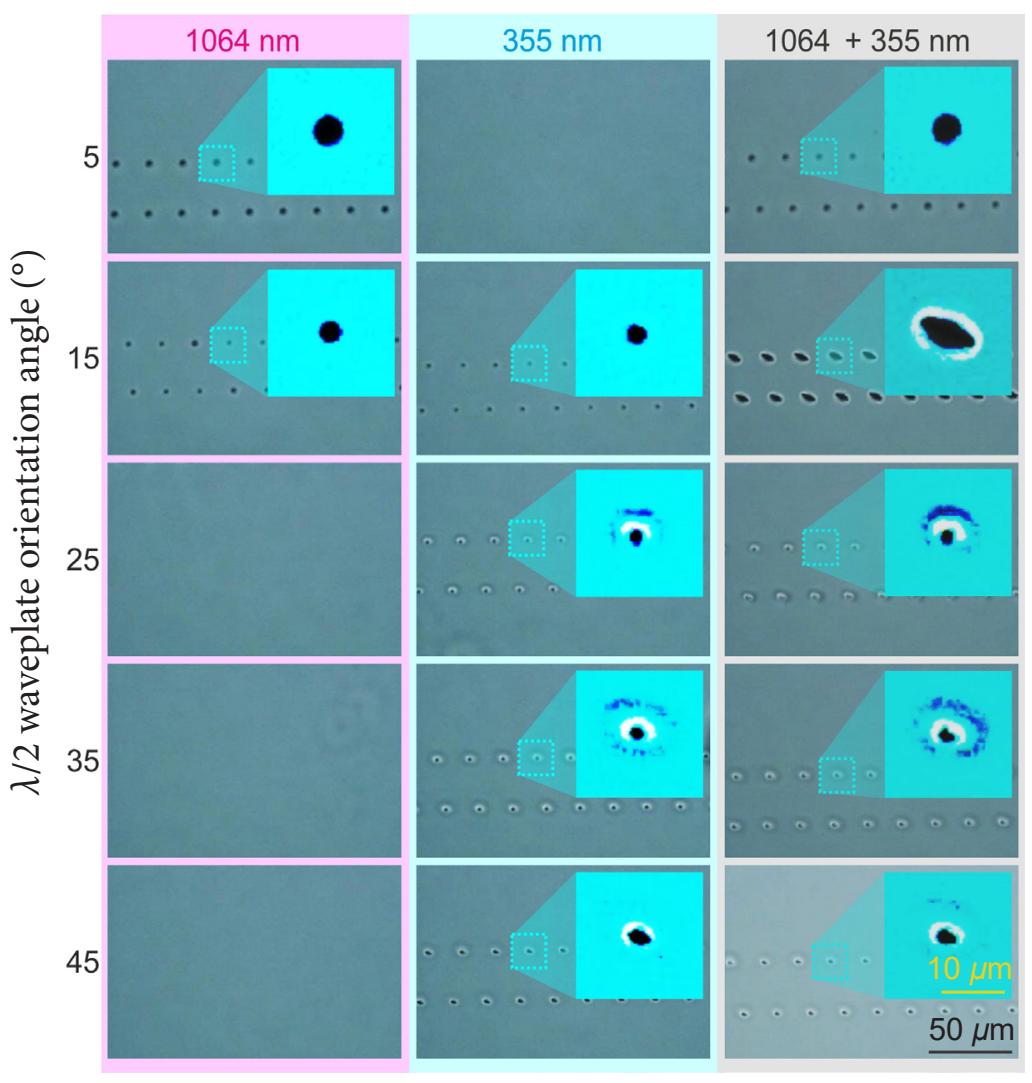

Fig. 3. Microscope images of intra-volume modifications in sapphire induced by laser \#1. Series of the modifications were produced varying pulse energy of the laser by HWP rotation. Singlepulse at 1064 and $355 \mathrm{~nm}$, as well as double-pulse $(355+1064 \mathrm{~nm}$, with a delay of $0.1 \mathrm{~ns}$ between pulses) irradiation regimes, were applied. Enlarged are images of selected modification spots. Coloured online.
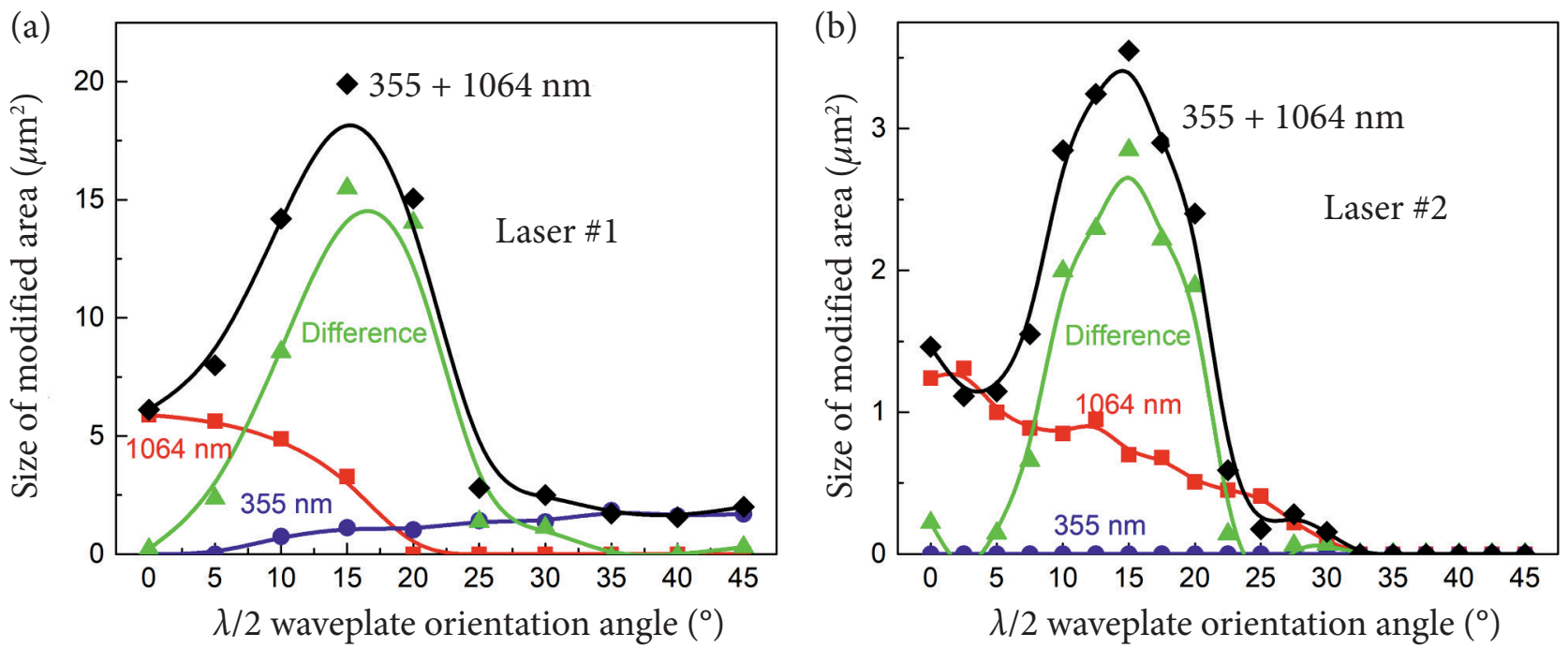

Fig. 4. Size of lateral intra-volume modifications in the sapphire wafer induced at various irradiation regimes, varying pulse energies by rotation of $\lambda / 2$ wavelength plate. The enhancement in the modification size due to double-pulse irradiation achieved by subtracting single pulse modification sizes: $S(1064+355 \mathrm{~nm})-S(1064 \mathrm{~nm})-$ $S(355 \mathrm{~nm})$. Adapted with permission from reference [33] under CC BY license, Springer Nature. Coloured online. 


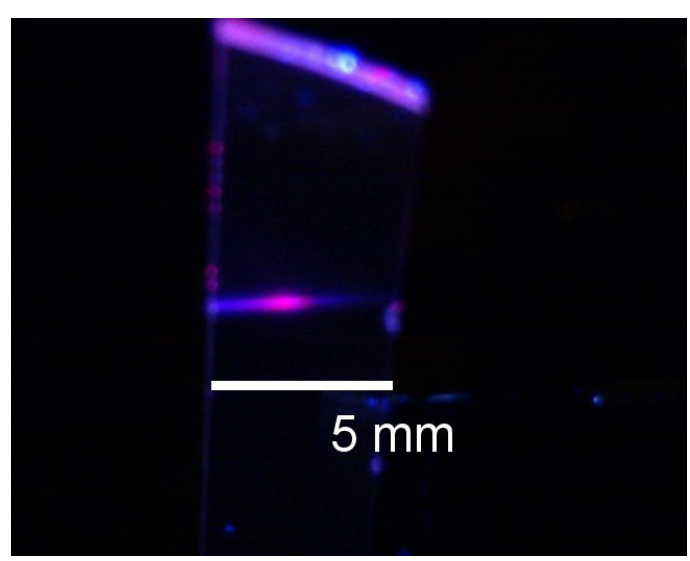

Fig. 5. CCD camera image of the photoluminescence track in sapphire under excitation with a focused picosecond laser beam. Coloured online.

enhanced intra-volume modifications of sapphire in the combined double-pulse two-wavelength irradiation regime.

\section{Discussion}

Intra-volume modifications and cracks observed in sapphire after intense laser irradiation are related to the energy that was highly localised when absorbed from laser pulses. The photon energy of fundamental IR and even the third harmonics at $355 \mathrm{~nm}$ of an $\mathrm{Nd}: \mathrm{YVO}_{4}$ laser is too low for direct single-photon excitation of the material. Therefore, various channels of multiphoton excitation should be considered.

Excitation of electrons from the valence band to the conduction band can be expressed by the rate equation [35]

$$
\frac{\partial n_{\mathrm{e}}}{\partial t}=\frac{n_{\mathrm{v}} n_{\mathrm{e}}}{n_{\mathrm{v}}}\left(W_{\mathrm{MPI}}+n_{\mathrm{e}} W_{\mathrm{AI}}\right)-\frac{n_{\mathrm{e}}}{\tau_{\mathrm{r}}},
$$

where $n_{\mathrm{e}}$ is the electron concentration in the conduction band, $n_{\mathrm{v}}$ is the initial electron concentration in the valence band, and $W_{\mathrm{MPI}}$ and $W_{\mathrm{AI}}$ are the rates of multi-photon ionisation and avalanche (impact) ionisation, respectively. The last term accounts for recombination of free electrons from the conduction band with a characteristic time $\tau_{\mathrm{r}}\left(\tau_{\mathrm{r}}=100 \mathrm{ps}\right.$ in sapphire [36]). The equation adequately describes the behaviour of sapphire during single pulse irradiation. Additional terms could be considered when two pulses with different wavelengths are applied.

\subsection{Multiphoton absorption of $U V$ and $I R$}

Considering the band gap of $8.80 \mathrm{eV}$, at least the eight-photon absorption (8PA) is required to generate free electrons using the $1064 \mathrm{~nm}$ radiation. Meanwhile, only three photons (3PA) of $355 \mathrm{~nm}$ radiation are enough to transfer an electron from the valence to the conduction band.

For $N$-photon absorption, the rate at which laser energy is absorbed by the unit volume of the material is

$$
\left(\frac{\mathrm{d} I}{\mathrm{~d} z}\right)_{\mathrm{MPI}}=-\sum_{N=1}^{\infty} \alpha_{N} I^{N}
$$

with $\alpha_{N}$ defined as the $N$-photon absorption coefficient and $I$ being the radiation intensity [37]. The dominant material dependence of $\alpha_{N}$ is through the energy band-gap and the $\mathrm{N}$-photon absorption coefficient decreases as $E_{\mathrm{g}}{ }^{4-5}$. The multi-photon absorption model of [37] was extended to the sapphire case by Arola et al. [38]. Using the Arola data for $\mathrm{N}$-photon absorption coefficients, the excitation processes of 8PA at $1064 \mathrm{~nm}\left(\alpha_{8}(1064)=4.5 \times 10^{-87} \mathrm{~cm}^{13} / \mathrm{W}^{7}\right)$ and $3 \mathrm{PA}$ at $355 \mathrm{~nm}\left(\alpha_{3}(355)=3.8 \times 10^{-24} \mathrm{~cm}^{3} / \mathrm{W}^{2}\right)$ have equal rate $\mathrm{d} I / \mathrm{d} z$ when the intensity is about $4 \times 10^{12} \mathrm{~W} / \mathrm{cm}^{2}$. However, according to our experimental data, neither 1064 nor $355 \mathrm{~nm}$ pulse could alone initiate crack formation in sapphire at that intensity.

By tuning the half-wave plate, we vary the ratio of initial pulse energy with the fundamental IR wavelength of $1064 \mathrm{~nm}(1.165 \mathrm{eV})$, which directly goes to the sample and to the part which is converted to the third harmonics at $355 \mathrm{~nm}(3.493 \mathrm{eV})$. The intensity ratio of UV to IR laser radiation grows up with the orientation angle, but a flux of high-energy photons never exceeded $7 \%$ of the IR photon flux within the range where the increased modification was observed in sapphire for dualwavelength irradiation. A quite minor attendance of UV photons provokes the significant increase of multi-photon excitation probability and at least four-time higher modification of the material.

At the used experimental conditions and applying multi-photon ionisation (MPI) coefficients according to simulation [38], the upper limit for the free electron concentration was estimated. With the maximum pulse energy used in the experiments 
of $68 \mu \mathrm{J}$, the total number of photons per pulse (at $1064 \mathrm{~nm}$ ) was below $3.6 \times 10^{14}$. However, their density in a focal volume was as high as $10^{23} \mathrm{~cm}^{-3}$. In the case of 8PA at $1064 \mathrm{~nm}$, the upper limit for the free electron concentration could be $\mathrm{N}^{8}{ }_{1064}=10^{17}-10^{20} \mathrm{~cm}^{-3}$, depending on the HWP orientation (pulse energy). The cumulative action of both wavelengths disappeared when the concentration $N^{8}{ }_{1064}$ fell below $10^{16} \mathrm{~cm}^{-3}$. In the case of 3PA at $355 \mathrm{~nm}$, the upper limit for free-electron concentration was $\mathrm{N}_{355}^{3}=10^{10}-10^{13} \mathrm{~cm}^{-3}$ depending on the HWP orientation (pulse energy). At the maximum UV laser pulse energy (whole IR pulse energy was converted to UV), the maximum free-electron concentration $\mathrm{N}_{355}^{3}$ was not more than $10^{15} \mathrm{~cm}^{-3}$.

Delay between UV and IR laser pulses was set to $\sim 100$ ps during the experiments. That eliminates the virtual interaction of IR and UV laser pulses of 10 ps duration in the multi-colour multi-photon absorption. The multi-photon inter-band excitation through virtual intermediate states cannot explain the 'resonant' behaviour of the internal modifications in sapphire observed in our experiments. Therefore, other mechanisms than multi-photon absorption should be considered to explain intravolume modifications leading to crack formation in sapphire.

\subsection{Critical plasma concentration and impact ionisation}

At high laser intensities, the effects of free-electron absorption are expected to dominate the transmissivity. The intensity is high enough to create the initial seed plasma regardless of the band-gap value [39]. Transient transformation of dielectric material to a highly-absorbing metallic state occurs at intense laser excitation when the free-electron plasma reaches a critical concentration

$$
n_{\text {cr }}=\frac{\epsilon_{0} m_{\mathrm{e}} \omega_{0}^{2}}{\mathrm{e}^{2}},
$$

where $e$ is the electron charge, $m_{\mathrm{e}}$ is the electron mass, $\epsilon_{0}$ is the vacuum dielectric permittivity, $\omega_{0}=2 \pi c / \lambda_{0}, c$ is the speed of light, and $\lambda_{0}$ is the laser wavelength. The critical electron plasma density is $9.8 \times 10^{20} \mathrm{~cm}^{-3}$ for a laser wavelength of $\lambda_{0}=1064 \mathrm{~nm}$ and $8.8 \times 10^{21} \mathrm{~cm}^{-3}$ for a laser wavelength of $\lambda_{0}=355 \mathrm{~nm}$. The IR laser pulses were close to reaching the limit, and we experimentally observed internal modifications in sapphire using only the IR beam. The intensity of $355 \mathrm{~nm}$ radiation was much lower to get the critical plasma concentration. However, modifications in sapphire were produced as well at higher pulse energies using only UV laser pulses.

The enhanced excitation of sapphire in the twocolour regime could be a sequence of IR light absorption by free carriers (electrons in the conduction band) generated by three-photon absorption of UV light, followed by impact ionisation of additional free-carriers from the valence band.

Based on their modelling, Capuano et al. [40] claim that sapphire could be modified by the laser radiation only if avalanche ionisation is triggered in bulk. According to their data, a sudden increase in the electron density at the sapphire surface starts for electron density above $n_{\mathrm{e}} \approx 5 \times 10^{17} \mathrm{~cm}^{-3}$. Free electrons gain their kinetic energy absorbing photons. Free electron absorption leading to avalanche (impact) ionisation is proportional to the seed electron concentration and laser intensity and is described as

$$
\left(\frac{\mathrm{d} I}{\mathrm{~d} z}\right) \mathrm{AI}=\sigma_{\mathrm{ce}} n_{\mathrm{e}} I
$$

where $\sigma_{c e}$ is the free electron cross-section, $n_{\mathrm{e}}$ is the free electron concentration in the conduction band, $I$ is the laser radiation intensity, and $z$ is the laser propagation direction.

Karras et al. [41] estimated the free-electron cross-section in sapphire for the $800 \mathrm{~nm}$ wavelength to be equal to $1.25 \times 10^{-17} \mathrm{~cm}^{2}$. Depending on the predominant electron-phonon scattering mechanism (by acoustic phonons $\sim \Delta E^{-1 / 2}$ or ionised defects $\left.\Delta E^{3 / 2}[42]\right)$, the cross-section at the 1064 or $355 \mathrm{~nm}$ wavelengths could differ no more than 0.7-3.4 times. At our experimental conditions, considering the generation of seed electrons to the conduction band by 3PA of $355 \mathrm{~nm}$ pulse and later freeelectron absorption of $1064 \mathrm{~nm}$ photons, the upper limit of electron concentration in the conduction band could be $2 \times 10^{18} \mathrm{~cm}^{-3}$. That value is significantly less than the density of electrons generated by multi-photon absorption 8PA, even though we did not take into account the delay of $\sim 100$ ps between UV and IR pulses, and the concentration, in reality, would be much less due to relaxation. The insignificance of the avalanche process in multi-photon 
excitation of wide band-gap dielectrics at similar experimental conditions was shown in [43] using a femtosecond pump-probe interferometry technique to measure the density of carriers excited by ultrashort intense laser pulses.

\subsection{Self-trapped excitons}

The transient energetic levels in the band-gap could work as intermediate states during multi-photon absorption. Free electrons from the conduction band can be captured very fast (150 fs) in fused silica by the formation of self-trapped excitons (STE) [44, 45. From time-dependent $\mathrm{THz}$ probe measurements, a typical carrier lifetime of 20 ps was observed in $\alpha-\mathrm{Al}_{2} \mathrm{O}_{3}$; the lifetime in the high-purity sapphire was found to be close to $200 \mathrm{ps}$ [36]. Pumpprobe experiments in $\mathrm{Al}_{2} \mathrm{O}_{3}$ suggest that no trapping occurs on the timescale of few tens of picoseconds or that the electrons form very shallow traps [46]. Small binding energies of excitons in $\alpha-\mathrm{Al}_{2} \mathrm{O}_{3}$ are confirmed by reflectivity measurement in [47]. Selftrapping energy of $0.13 \mathrm{eV}$ with a barrier for trapping of $0.19 \mathrm{eV}$ was calculated by [48] and confirmed experimentally by [49]. Recombination of STE in sapphire is responsible for the luminescence peak at $7.5 \mathrm{eV}$ [49]. The energy deficit due to localisation is $1.3 \mathrm{eV}$. For comparison, the exciton absorption energy is $9.3 \mathrm{eV}$ in crystalline silica $\left(\mathrm{SiO}_{2}\right)$, and the selftrapped exciton emission takes place at $2.8 \mathrm{eV}$ [50].

Temporal delay between UV and IR pulses of 100 ps was used in our experiments. It was selected for the maximal intra-volume modification in sapphire using two-pulse two-colour irradiation [33]. The optimal delay corresponds well with the trapping time in sapphire [44]. However, the Stokes shift for self-trapped excitons in $\alpha-\mathrm{Al}_{2} \mathrm{O}_{3}$ is much less than in $\mathrm{SiO}_{2}$. The involvement of shallow energetic levels in multi-photon ionisation cannot provide significant gain in the free-electron generation. Therefore, we exclude STE as a potential channel of extraordinal excitation in sapphire under our experimental conditions.

\subsection{Multi-photon absorption involving deep local energetic levels in the band-gap}

3PA at $355 \mathrm{~nm}$ and 8PA at $1064 \mathrm{~nm}$ are multi-photon excitation channels that work separately and are experimentally easy to test (data included).
Other options for multi-photon excitation using both photon energies and the minimum number of photons could be 2PA $(355 \mathrm{~nm})+3 \mathrm{PA}$ $(1064 \mathrm{~nm})$ and 1PA $(355 \mathrm{~nm})+6 \mathrm{PA}(1064 \mathrm{~nm})$ to bridge the band-gap of $8.8 \mathrm{eV}$. More options also exist, but the probability of such processes decreases rapidly with a larger number of photons involved. Such combined multi-photon excitation, in principle, takes place through virtual intermediate states. However, there was a 100 ps temporal delay between the UV laser pulse (first) and the IR laser pulse in our experiments. Therefore, the real intermediate states (energy level in the band-gap) should be considered. The two-step absorption spectroscopy method was developed in [54] to investigate intrinsic and impurities defects in semiconductors.

Intrinsic defects are usually present in all wide band-gap materials like sapphire. Oxygen vacancies $V_{\mathrm{O}}{ }^{2+}$ in various charge states ( $F$ centres) and oxygen bi-vacances $F_{2}$ are the most convenient defects in sapphire [ 58, 63, 64, 62]. In addition, UV light, similar to the action of more energetic photons [62] or neutrons [64], is able to generate transient colour centres in sapphire. A delay of 100 ps is long enough for local arrangement transformation of a colour centre after capturing an electron. IR light could be step-wise absorbed more efficiently from the valence band through colour centres to the conduction band.

In the case of two-step absorption through a real deep energetic level (colour centre) in the band gap of sapphire, two options, described above, were analysed in details:

If the excitation process includes photons of various energies, 1PA at $355 \mathrm{~nm}(3.493 \mathrm{eV})$ takes place from the valance band to the colour centre $F 1$. The next step should consist of at least 6PA at $1064 \mathrm{~nm}(6 \times 1.165=6.99 \mathrm{eV})$ to reach the conduction band by an electron. As real energetic levels are involved as intermediate levels in multi-photon absorption, the excitation channel efficiency is limited to the concentration of particular kind of colour centres. Intensive laser radiation could completely fill them by transferring a significant number of electrons from the valance band or making colour centres vacant by transferring all captured electrons to the conduction band.

The energy absorption rate for the transition between the upper valence band VB and colour centre $F 1$ is 


$$
\frac{\mathrm{d} I_{355}}{\mathrm{~d} t}=\alpha_{1}(355) \times I_{355} \propto 1-P_{F 1}
$$

where $I_{355}$ is the intensity of UV laser beam at $355 \mathrm{~nm}\left[\mathrm{~W} / \mathrm{cm}^{2}\right]$, and $\alpha_{1}(355)$ is the linear (onephoton) absorption (1PA) coefficient $\left[\mathrm{cm}^{-1}\right]$ for the transition between the upper valence band and the colour centre $F 1$. The population of the colour centre $P_{F_{1}}$ is

$$
P_{F 1}=\frac{n_{F 1}}{N_{F 1}},
$$

where $N_{F 1}$ is the concentration of colour centres $F 1\left[\mathrm{~cm}^{-3}\right]$, and $n_{F 1}$ is the concentration of colour centres that captured electrons from the valence band ('occupied') $\left[\mathrm{cm}^{-3}\right]$. The difference $\left(1-P_{F 1}\right)$ is a measure of unoccupied colour centres $F 1$.

The absorption rate from the centre to the conduction band could be described as

$$
\frac{\mathrm{d} I_{1064}}{\mathrm{~d} t}=\alpha_{6}(1064) \times I_{1064}^{6} \propto P_{F 1},
$$

where $I_{1064}$ is the intensity of the IR laser beam at $1064 \mathrm{~nm}\left[\mathrm{~W} / \mathrm{cm}^{2}\right]$, and $\alpha_{6}(1064)$ is the six-photon absorption (6PA) coefficient $\left[\mathrm{cm}^{9} / \mathrm{W}^{5}\right]$ for the transition between the colour centre $F 1$ and the conduction band.

The whole $1+6$ photon excitation process (channel) could be described by the excitation rate

$$
A_{1,6}=\alpha_{1}(355) \times I_{355}\left(1-P_{F 1}\right)+\alpha_{6}(1064) \times I_{1064}^{6} \times P_{F 1} .
$$

Considering two-photon absorption (2PA) of the $355 \mathrm{~nm}$ radiation from the valence band to the colour centre $F 2$, the next step should include at least $3 \mathrm{PA}$ at $1064 \mathrm{~nm}(3 \times 1.165=3.495 \mathrm{eV})$ to reach the conduction band by an electron.

The energy absorption rate for the transition between the upper valence band VB and colour centre $F 2$ is described as

$$
\frac{\mathrm{d} I_{355}}{\mathrm{~d} t}=\alpha_{2}(355) \times I_{355}^{2} \propto 1-P_{F 2},
$$

where $\alpha_{2}(355)$ is the two-photon absorption (2PA) coefficient $[\mathrm{cm} / \mathrm{W}]$ for the transition between the upper valence band and colour centre F2. The population of the colour centre $P_{F 2}$ is

$$
P_{F 2}=\frac{n_{F 2}}{N_{F 2}}
$$

where $N_{F 2}$ is the concentration of colour centres F2 $\left[\mathrm{cm}^{-3}\right]$, and $n_{F 2}$ is the concentration of colour centres electron-captures from the valence band $\left[\mathrm{cm}^{-3}\right]$.

The absorption rate from the centre to the conduction band could be described as

$$
\frac{\mathrm{d} I_{1064}}{\mathrm{~d} t}=\alpha_{3}(1064) \times I_{1064}^{3} \propto P_{F 2},
$$

where $\alpha_{3}(1064)$ is the three-photon absorption (3PA) coefficient $\left[\mathrm{cm}^{3} / \mathrm{W}^{2}\right]$ for the transition between the colour centre $F 2$ and conduction band CB.

The whole $2+3$ photon excitation channel could be described as

$$
A_{2,3}=\alpha_{2}(355) \times I_{355}^{2}\left(1-P_{F 2}\right)+\alpha_{3}(1064) \times I_{1064}^{3} \times P_{F 2} .
$$

As the initial laser beam was split into two beams by HWP rotation with the later conversion of one beam from IR to UV, an increase in the intensity of one beam was related to a decrease in a portion of the initial laser pulse directed to the second beam. We can expect domination of $\mathrm{VB} \rightarrow F$-centre transitions when the UV beam is more intense, and the opposite, $F$-centre $\rightarrow \mathrm{CB}$ transfer should prevail at high-intensity IR beam. The population of the centre involved in the two-step multi-photon excitation of free electrons varies with the ratio of intensities of IR and UV pulses. Therefore, an experimentally 'resonant' increase of multiphoton absorption and related crack formation was observed in sapphire.

Based on the Arola simulation [38], coefficients of multi-photon absorption were selected, which correspond to experimental data of [41]:

$$
\begin{aligned}
& \text { - } \alpha_{1}(355)=2.80 \mathrm{~cm}^{-1}, \\
& \text { - } \alpha_{2}(355)=8.5 \times 10^{-8} \mathrm{~cm} / \mathrm{W}, \\
& \text { - } \alpha_{3}(1064)=1.4 \times 10^{-23} \mathrm{~cm}^{3} / \mathrm{W}^{2}, \\
& \text { - } \alpha_{6}(1064)=3.05 \times 10^{-67} \mathrm{~cm}^{9} / \mathrm{W}^{5} .
\end{aligned}
$$

The energy absorption (excitation) rate was calculated according to Eqs. (8) and (12) using 
the experimental data of pulse energies (Fig. 2), converted to intensities of the IR and UV beams for both laser set-ups: laser \#1 and laser \#2.

The simulation results for $1 \mathrm{PA}+6 \mathrm{PA}$ and $2 \mathrm{PA}+3 \mathrm{PA}$ models are presented in Figs. 6-8. They are compared to the modification area size gained due to the combined use of two-colour laser pulses (difference in Fig. 4). The size of modifications inside sapphire is directly related to the absorbed laser energy when a particular threshold is exceeded.

We achieved a pretty good agreement in the 'resonance shape' of the absorbed energy dependences on the HWP orientation angle (Fig. 6) and intensities of IR and UV pulses (Figs. 凤, 8). In both cases, the input of the 1PA+6PA process prevails over that of the $2 \mathrm{PA}+3 \mathrm{PA}$ process, indicating that the density of $F 1$ centres is higher than that of $F 2$ centres. The enhanced absorption and modification size were observed in a very narrow UV and IR pulse intensities window. That indicates a complex interplay between multi-photon excitation by photons on different energies.

The selection of colour centres that act as intermediate levels in the two-step multi-photon excitation is not a trivial task. Sapphire possesses a broad range of intrinsic defects, which also differ in their charge states [51]. Significant differences in excitation and emission spectra evidence large (a)

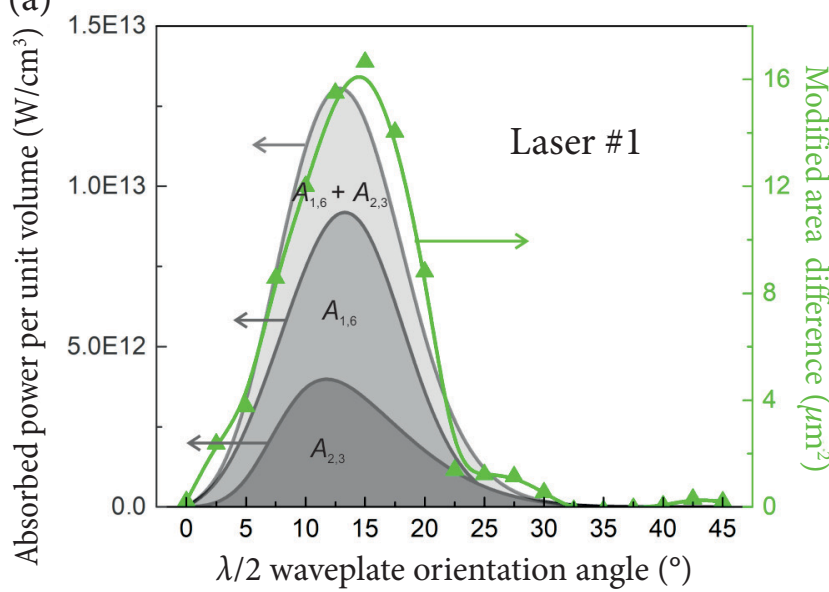

(b)

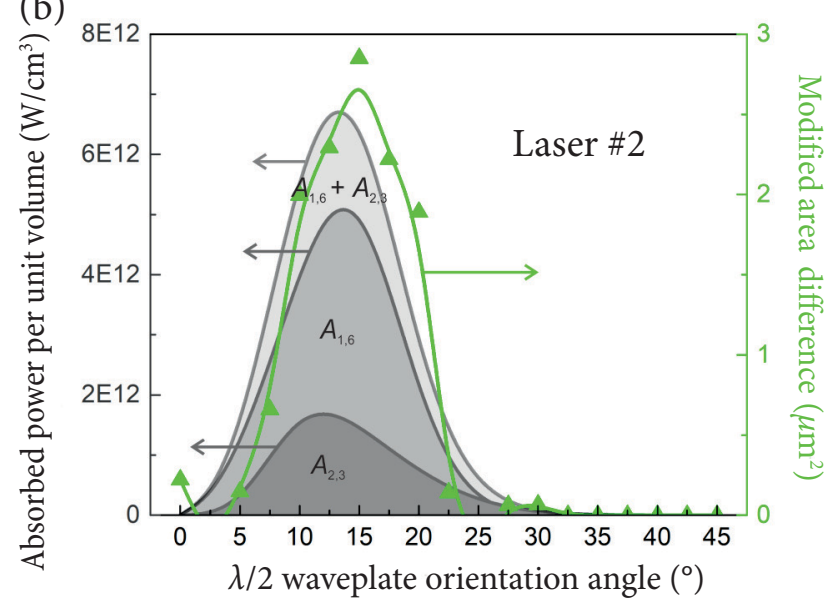

Fig. 6. Absorbed power per unit volume $\left[\mathrm{W} / \mathrm{cm}^{3}\right]$ for the two-step multi-photon $1 \mathrm{PA}(355)+6 \mathrm{PA}(1064)$ and $2 \mathrm{PA}(355)+3 \mathrm{PA}(1064)$ excitation channels in sapphire on the ratio of UV and IR pulse intensities, set by the orientation angle of the $\lambda / 2$ waveplate (HWP), compared to the experimental modified area size (dots), gained by the combined action of both laser pulses from (a) laser \#1 and (b) laser \#2. Coloured online.
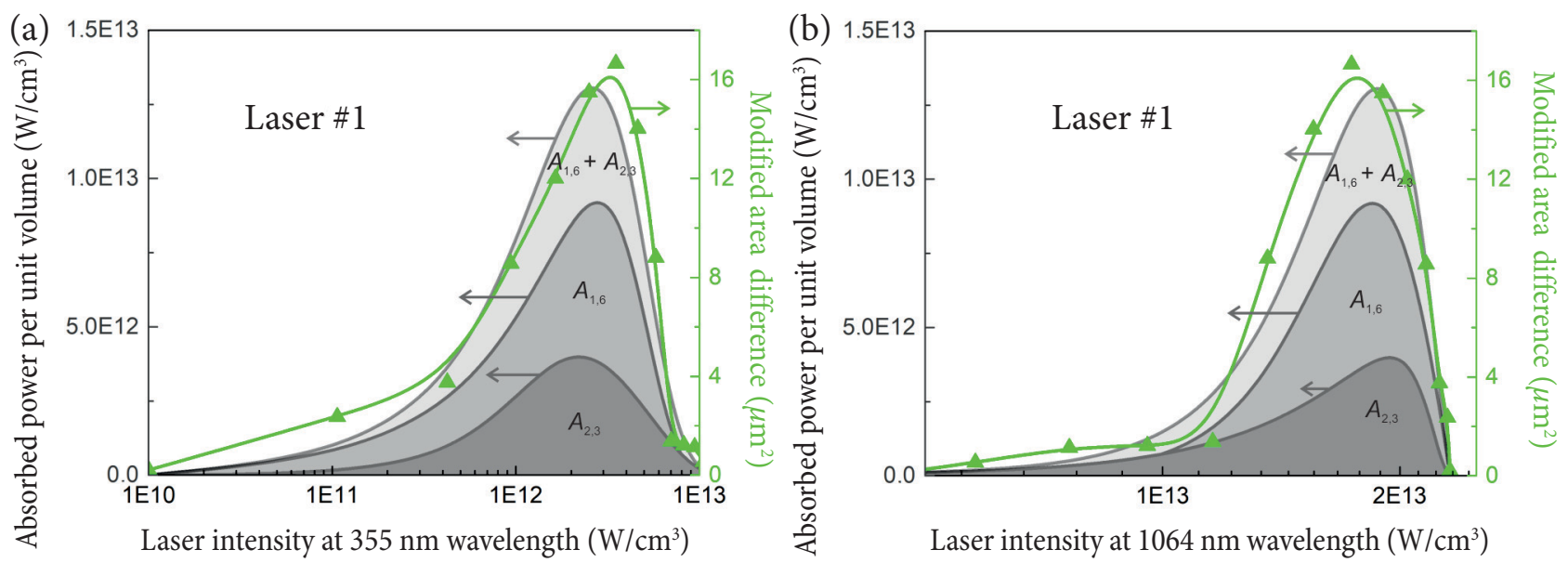

Fig. 7. Absorbed power per unit volume $\left[\mathrm{W} / \mathrm{cm}^{3}\right]$ for the two-step multi-photon $1 \mathrm{PA}(355)+6 \mathrm{PA}(1064)$ and 2PA(355)+3PA(1064) excitation channels in sapphire on the intensity of UV (a) and IR (b) pulses, compared to the experimental modified area size (dots), gained by the combined action of both laser pulses (laser \#1). Coloured online. 

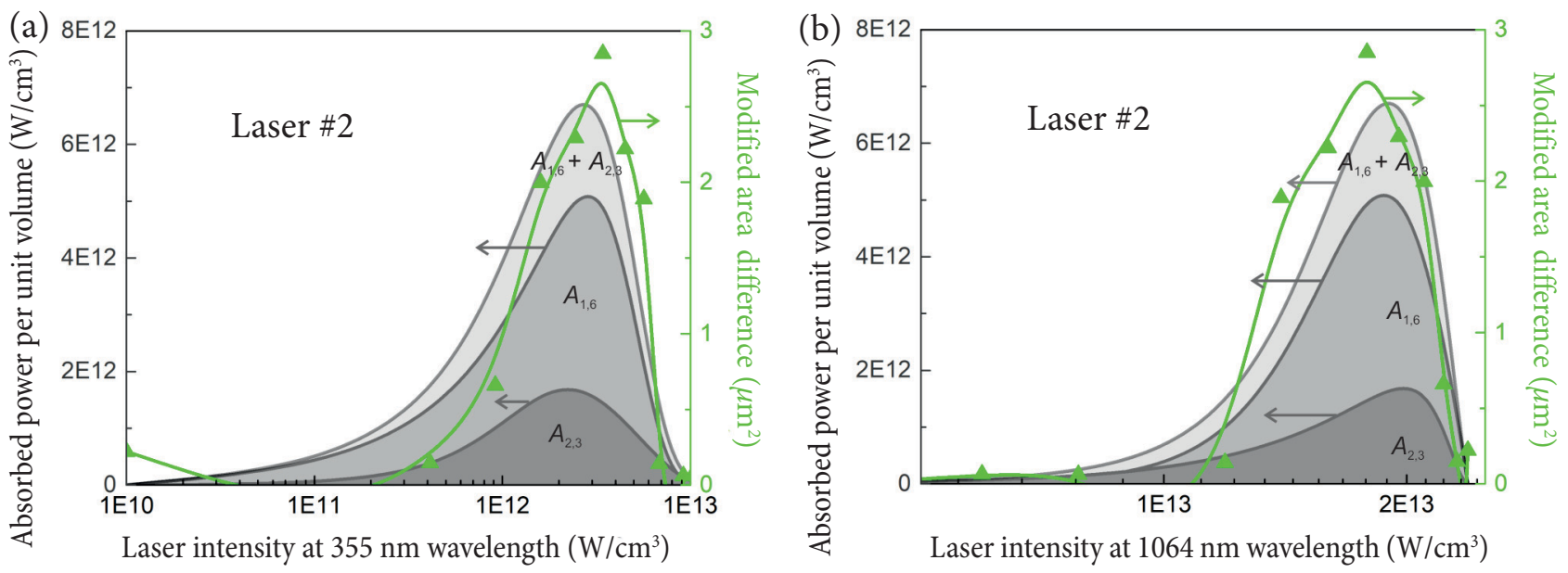

Fig. 8. Absorbed power per unit volume $\left[\mathrm{W} / \mathrm{cm}^{3}\right]$ for the two-step multi-photon $1 \mathrm{PA}(355)+6 \mathrm{PA}(1064)$ and $2 \mathrm{PA}(355)+3 \mathrm{PA}(1064)$ excitation channels in sapphire on the intensity of UV (a) and IR (b) pulses, compared to the experimental modified area size (dots), gained by the combined action of both laser pulses (laser \#2). Coloured online.

transformations in ion configuration with a captured charge (electron) [52]. Detailed spectroscopic investigations are needed to build and approve the configuration model of a centre with the strong local electron-phonon interaction [53, 54. The Stokes shift reflects self-compensation of both the charge and local lattice deformations. Therefore, even knowing excitation energy $\mathrm{VB} \rightarrow F-$ centre, it is impossible to directly distract from the band-gap the energy distance to the opposite conduction band at the $\Gamma$ point. The conduction band for $\alpha-\mathrm{Al}_{2} \mathrm{O}_{3}$ near the $\Gamma$ point is localised on $\mathrm{Al} 3 \mathrm{~s}$ states. The upper valence bands are oxygen non-bonding $\mathrm{p}$ states [55]. The symmetry selection rules should be applied for optical transitions, as well.

Oxygen vacancy is the intrinsic defect with the lowest formation energy in $\alpha-\mathrm{Al}_{2} \mathrm{O}_{3}$ [56]. We can expect the highest concentration of those defects in the material. The $V_{\mathrm{O}}$ defect creates energetic levels deep in the band gap, and their position depends on the charge state of the defect. A vacancy with two captured electrons is neutral $V_{\mathrm{O}}{ }^{2+}+\rightarrow V_{\mathrm{O}}{ }^{0}$ and is called $F$ centre.

Position of $V_{\mathrm{O}}{ }^{0}$ at about $2.8-3.2 \mathrm{eV}$ above the valence band maximum is confirmed experimentally [32, 57] and by simulations [58, 52]. $5.6 \mathrm{eV}$ distance to the conduction band is estimated, but at least one-photon transitions from the ground state $A 1$ of the oxygen vacancy $V_{\mathrm{O}}{ }^{0}$ ( $F$ centre) to the conduction band are forbidden. The transition to $T 2$ state $6.3 \mathrm{eV}$ above $A 1$ state overlapping with the conduc- tion band is a way of free-electron generation [58]. The latter leads to excitation of photoluminescence at $3.85 \mathrm{eV}$ [59, 60]. Such scheme of the $F$ centre energetic levels in $\alpha-\mathrm{Al}_{2} \mathrm{O}_{3}$ agrees well with the early work of Evans et al. [61] just interpreting it as $\mathrm{F}^{+}$centre.

Based on our experimental results and data available in the literature, the energy level scheme and configuration model of the $V_{\mathrm{O}}$ centre involved in the two-step multi-photon excitation process 1PA $(355 \mathrm{~nm})+6 \mathrm{PA}(1064 \mathrm{~nm})$ in sapphire were prepared (Fig. 9). The absorption of one photon at $355 \mathrm{~nm}$ leads to the electron transition from the valance band to the $V_{\mathrm{O}}{ }^{+}$centre. The captured electron recharges the centre to $V_{\mathrm{O}}{ }^{0}$ with the corresponding defect environment transformation in 100 ps delay until the IR laser pulse arrives. Six-photon absorption of the $1064 \mathrm{~nm}$ radiation by the electron takes place leading to an excited $T 2$ state of the centre $V_{\mathrm{O}}^{0}$, energetically overlapping with the conduction band. Direct transfer to the conduction band is symmetry-forbidden. The electron may escape from the defect due to electron-electron scattering. The charge status of oxygen vacancy is changed, and ions around the defect relax again to the stationary position of the $V_{\mathrm{O}}{ }^{+}$centre. A free electron could be radiatively captured from the conduction band to the $V_{\mathrm{O}}{ }^{+}$centre, emitting UV luminescence centred at $3.85 \mathrm{eV}$, transforming the centre to the $V_{\mathrm{O}}{ }^{0}$ state.

Mono-vacancies of oxygen $V_{\mathrm{O}}$ are primary defects in sapphire generated by irradiation with high-energy photons or ions [ 51, 62, At high irradiation doses, the concentration of single defects 

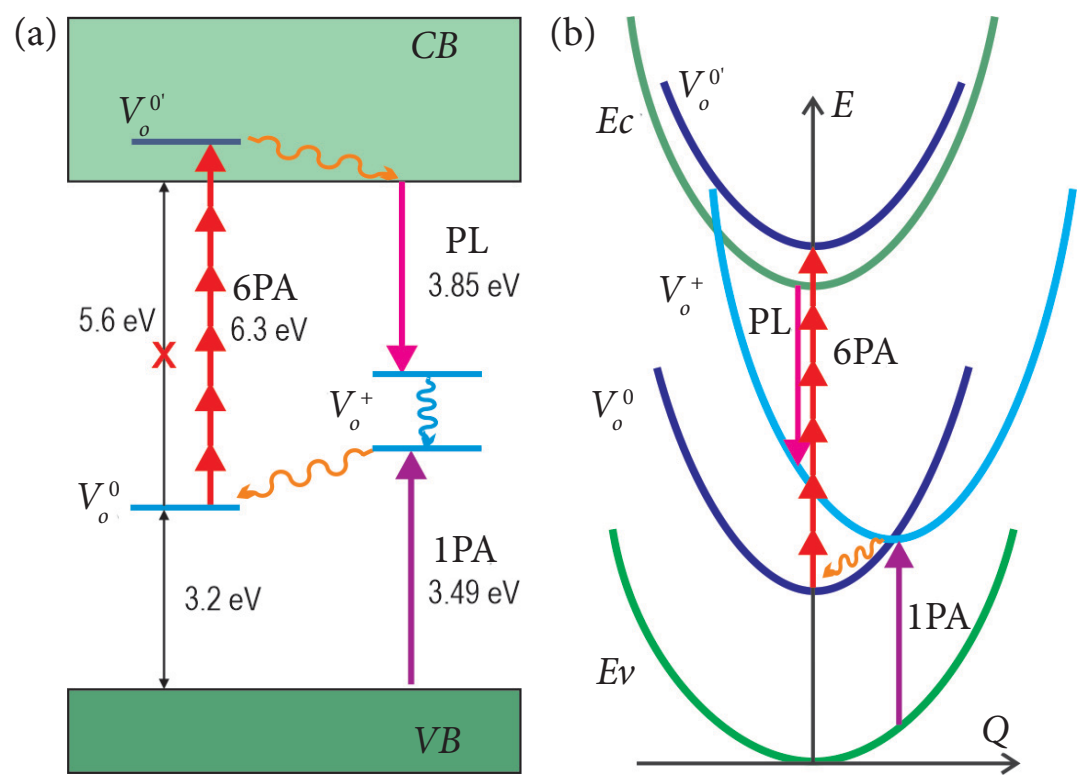

Fig. 9. Energy level diagram and configuration model of the $V_{\mathrm{O}}$ centre involved in the two-step multi-photon excitation process 1PA $(355 \mathrm{~nm})+6 \mathrm{PA}(1064 \mathrm{~nm})$ in sapphire. Coloured online.

becomes large and neighbouring defects form more complex $F$ centre aggregates. Aggregate $F_{2}, F_{2}{ }^{+}$and $\mathrm{F}_{2}^{2+}$ centres are oxygen divacancies that trap four, three or two electrons, respectively [62]. Therefore, we consider $F_{2}$ complexes as an additional group of energetic levels in the band-gap acting as intermediate levels in the two-step multi-photon excitation of the material.

$\mathrm{F}_{2}^{2+}$ centre is responsible for an optical absorption band at 2.75-2.8 eV [63-65]. That suggests the minimum distance from the valence band of $6.05 \mathrm{eV}$. This energy gap could be covered by two photons with an energy of $3.493 \mathrm{eV}(355 \mathrm{~nm})$. The absorption band of $3.47 \mathrm{eV}$ and photoluminescence at $380 \mathrm{~nm}(3.26 \mathrm{eV})$ are attributed to the $F_{2}^{+}$ centre $[51,63,64]$.

Combining our experimental results and data available in the literature, the energy level scheme of the $F_{2}$ centre involved in the two-step multi-photon excitation process 2PA $(355 \mathrm{~nm})+3 \mathrm{PA}(1064 \mathrm{~nm})$ in sapphire was prepared (Fig. 10).

Absorption on two photons at $355 \mathrm{~nm}$ leads to electron transition from the valance band to the $F_{2}{ }^{2+}$ centre. The captured electron recharges the centre to $\mathrm{F}_{2}{ }^{+}$state with the corresponding defect environment transformation in 100 ps delay until the IR laser pulse arrives. Three-photon absorption of the $1064 \mathrm{~nm}$ radiation takes place and the electron is transferred to the conduction band. The charge status of oxygen divacancy is changed again, and ions around the defect relax to the stationary position of $\mathrm{F}_{2}^{2+}$ centre. A free electron could be radiatively captured from the conduction band to the $\mathrm{F}_{2}{ }^{+}$centre, emitting UV luminescence centred

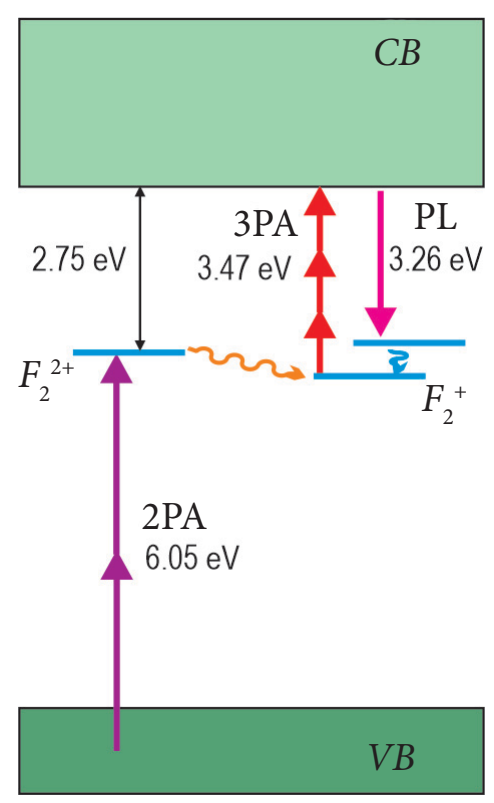

Fig. 10. Energy level scheme of $\mathrm{F}_{2}$ centre involved into the twostep multi-photon excitation process $2 \mathrm{PA}(355 \mathrm{~nm})+3 \mathrm{PA}$ $(1064 \mathrm{~nm})$ in sapphire. Coloured online. 
at $3.26 \mathrm{eV}(380 \mathrm{~nm})$, close to the luminescence observed during laser treatment of sapphire in our experiments. Data available from our experiments and literature are not sufficient to predict the configuration scheme of the $F_{2}$ centre. Comparing the input of $1 \mathrm{PA}+6 \mathrm{PA}$ and 2PA+3PA processes into the two-step multi-photon absorption rate (Figs. 6-8), the first one has higher efficiency, which is consistent with a natural ratio in the density of mono- and divacancies of oxygen in the material.

Why could intra-volume modifications of sapphire be enhanced more than four times if we consider the two-step multi-photon absorption through colour centres as intermediate levels in the band gap? The effect to free-electron density in the conduction band could not be stronger than the concentration of $F$ centres.

Defect level density as high as $1.6 \times 10^{19} \mathrm{~cm}^{-3}$ was measured at approximately $3.0 \mathrm{eV}$ below the conduction band in the bulk of $\mathrm{Al}_{2} \mathrm{O}_{3}$ films [58]. The high-quality epitaxy sapphire wafers are less defective. However, as oxygen vacancy $V_{\mathrm{O}}$ has the lowest formation energy in $\alpha-\mathrm{Al}_{2} \mathrm{O}_{3}$, they are easily produced by irradiation with high-energy photons. We can expect the generation of $V_{\mathrm{O}}$ defects irradiating with UV laser pulses. Absorption bands related to oxygen monovacancies in sapphire are in the UV spectral range, and that kind of modification of the material cannot be visually inspected. However, intense UV luminescence was observed during laser processing, evidencing the existence of $V_{\mathrm{O}}$ defects and their relaxation.

The experimentally measured and theoretically estimated lifetime of electrons on the localised state, such as the $F^{+}$colour centre, is a few nanoseconds [61], much longer than the pulse duration of $10 \mathrm{ps}$ and the delay between UV and IR pulses of about 100 ps. That facilitates the accumulation of electrons trapped on $F$ centres until more intense IR pulses arrive at the material.

The modification enhancement effect is observed in a narrow, limited range of intensities for UV and IR laser pulses (Figs. 7, 8). Under these conditions, the ratio of UV photons is no more than $10 \%$ of IR photons, which could not be explained by the 1:6 and 2:3 ratio in the discussed two-step excitation processes.

Therefore, the final picture of the sapphire excitation using intensive two-colour, two-pulse laser irradiation includes the following:
- three-photon $(355 \mathrm{~nm})$ generation of seed electrons in the conduction band;

- part of that excitation leads to the formation of transient colour centres (oxygen vacancies);

- recharging existing and new transient colour centres by UV photons lifting electrons from the valence band to the $V_{\mathrm{O}}{ }^{+}$and $\mathrm{F}_{2}{ }^{2+}$ centres, which relax to the $V_{\mathrm{O}}{ }^{0}$ and $F_{2}{ }^{+}$centres in $\sim 100 \mathrm{ps}$;

- eight-photon absorption of IR laser pulses (1064 $\mathrm{nm})$ between the valence and conduction bands;

- lifting electrons, captured at the $V_{\mathrm{O}}{ }^{0}$ and $F_{2}{ }^{+}$ centres, to the conduction band by multi-photon absorption of IR pulse;

- all the processes above facilitate high seedelectron density to ignite the impact ionisation by the remaining IR laser photons;

- irreversible modifications of the material results from the explosive growth of free-electron density above the critical plasma concentration in the focal volume of sapphire.

The minimal intensities of UV and IR pulses are required to trigger the whole process. Our experimental conditions tunning the IR and UV pulses intensities in the opposite direction by the HWP rotation lead to the 'resonant' behaviour of the material response.

\section{Conclusions}

The two-colour (wavelengths of 1064 and $355 \mathrm{~nm}$ ) double-pulse (inter-pulse delay of $0.1 \mathrm{~ns}$ ) combined picosecond laser irradiation was used to initiate intra-volume modifications (directional cracks) in single-crystal sapphire wafers. A significant increase of the modification area was experimentally observed when intensities of combined IR and UV laser beams were within a narrow window. The energies of IR $(1.165 \mathrm{eV})$ and UV $(3.493 \mathrm{eV})$ photons are much below the band gap $(8.8 \mathrm{eV})$ of sapphire, and various multi-photon excitation mechanisms responsible for the enhancement were analysed.

Besides the three-photon absorption of UV pulses and eight-photon absorption of IR pulses between the valence and conduction bands, the twostep multi-photon absorption through energy levels of colour centres was investigated.

Two pairs of intrinsic defects in different charge states could be responsible for the increased excitation rate at particular experimental conditions with 
a non-monotonous response to the ratio of UV to IR intensities.

The two-step multi-photon absorption process of $1 \mathrm{PA}(355 \mathrm{~nm})+6 \mathrm{PA}(1064 \mathrm{~nm})$ through $V_{\mathrm{O}}^{+} \leftrightarrow V_{\mathrm{O}}^{0}$ monovacancies of oxygen was modelled. The scheme of energy levels involved in the excitation and relaxation process and the corresponding configuration model were built.

The two-step multi-photon absorption process of $2 \mathrm{PA}(355 \mathrm{~nm})+3 \mathrm{PA}(1064 \mathrm{~nm})$ through $\mathrm{F}_{2}{ }^{2+} \leftrightarrow \mathrm{F}_{2}{ }^{+}$divacancies of oxygen was modelled. The scheme of energy levels involved in the excitation was prepared. The 1PA + 6PA absorption channel has higher efficiency than 2PA + 3PA, consistent with a natural ratio in the density of monoand divacancies of oxygen in the sapphire.

All the excitation processes above facilitate high seed-electron density to ignite the impact ionisation by the remaining IR laser photons, leading to irreversible modifications in the focal volume of sapphire. The minimal intensities of UV and IR pulses are required to trigger the whole process, evidencing the 'resonant' behaviour of the material response on the IR and UV pulses intensities.

\section{References}

[1] M. Yoshimoto, K. Yoshida, H. Maruta, Y.Hishitani, H. Koinuma, S. Nishio, M. Kakihana, and T. Tachibana, Epitaxial diamond growth on sapphire in an oxidising environment, Nature 399, 340342 (1999), https://doi.org/10.1038/20653

[2] P. Dragic, T. Hawkins, P. Foy, S. Morris, and J. Ballato, Sapphire-derived all-glass optical fibres, Nat. Photonics 6, 629-635 (2012), https:// doi.org/10.1038/nphoton.2012.182

[3] R. Yamauchi, Y. Hamasaki, T. Shibuya, A. Saito, N. Tsuchimine, K. Koyama, A. Matsuda, and M. Yoshimoto, Layer matching epitaxy of $\mathrm{NiO}$ thin films on atomically stepped sapphire (0001) substrates, Sci. Rep. 5, 14385 (2015), https://doi. org/10.1038/srep14385

[4] H. Liu and D. Chi, Dispersive growth and laser-induced rippling of large-area single layer $\mathrm{MoS}_{2}$ nanosheets by CVD on c-plane sapphire substrate, Sci. Rep. 5, 11756 (2015), https://doi. org/10.1038/srep11756
[5] A. Tanaka, R. Chen, K.L. Jungjohann, and S.A. Dayeh, Strong geometrical effects in submillimeter selective area growth and light extraction of GaN light emitting diodes on sapphire, Sci. Rep. 5, 17314 (2015), https://doi.org/10.1038/ srep17314

[6] G. Li, W. Wang, W. Yang, Y. Lin, H. Wang, Z. Lin, and S. Zhou, GaN-based light-emitting diodes on various substrates: a critical review, Rep. Prog. Phys. 79, 56501 (2016), https://doi. org/10.1088/0034-4885/79/5/056501

[7] T. Vodenitcharova, L.C. Zhang, I. Zarudi, Y. Yin, H. Domyo, T. Ho, and M. Sato, The effect of anisotropy on the deformation and fracture of sapphire wafers subjected to thermal shocks, J. Mater. Process. Technol. 193, 52-62 (2007), https://doi. org/10.1016/j.jmatprotec.2007.03.125

[8] R.W. Dreyfus, F. McDonald, and R.J. von Gutfeld, Laser energy deposition at sapphire surfaces studied by pulsed photothermal deformation, Appl. Phys. Lett. 50, 1491 (1987), https://doi. org/10.1063/1.97809

[9] D. Ashkenasi, A. Rosenfeld, H. Varel, M. Wähmer, and E.E. Campbell, Laser processing of sapphire with picosecond and sub-picosecond pulses, Appl. Surf. Sci. 120, 65-80 (1997), https://doi. org/10.1016/S0169-4332(97)00218-3

[10]H. Horisawa, H. Emura, and N. Yasunaga, Surface machining characteristics of sapphire with fifth harmonic YAG laser pulses, Vacuum 73, 661-666 (2004), https://doi.org/10.1016/j. vacuum.2003.12.065

[11]X.C. Wang, G.C. Lim, H.Y. Zheng, F.L. Ng, W. Liu, and S.J. Chua, Femtosecond pulse laser ablation of sapphire in ambient air, Appl. Surf. Sci. 228, 221-226 (2004), https://doi.org/10.1016/j.apsusc.2004.01.009

[12] M. Kumagai, N. Uchiyama, E. Ohmura, R. Sugiura, K. Atsumi, and K. Fukumitsu, Advanced dicing technology for semiconductor wafer - Stealth Dicing, IEEE Trans. Semicond. Manuf. 20, 259-265 (2007), https://doi.org/10.1109 ISSM.2006.4493065

[13]W.-S. Lei, A. Kumar, and R. Yalamanchili, Die singulation technologies for advanced packaging: 
A critical review, J. Vac. Sci. Technol. B 30, 40801

(2012), https://doi.org/10.1116/1.3700230

[14]W.H. Teh, D.S. Boning, and R.E. Welsch, Multistrata stealth dicing before grinding for singulation-defects elimination and die strength enhancement: Experiment and simulation, IEEE Trans. Semicond. Manuf. 28, 408-423 (2015), https://doi.org/10.1109/TSM.2015.2438875

[15]E. Ohmura, F. Fukuyo, K. Fukumitsu, and H. Morita, Modified-layer formation mechanism into silicon with permeable nanosecond laser, Int. J. Comput. Mater. Sci. Surf. Eng. 1, 677 (2007), https://doi.org/10.1504/IJCMSSE.2007.017923

[16]Y. Wang, A. Chen, S. Li, L. Sui, D. Liu, D. Tian, Y. Jiang, and M. Jin, Enhancement of laserinduced Fe plasma spectroscopy with dualwavelength femtosecond double-pulse, J. Anal. At. Spectrom. 31, 497-505 (2016), https://doi. org/10.1039/C5JA00420A

[17]S. Höhm, A. Rosenfeld, J. Krüger, and J. Bonse, Laser-induced periodic surface structures on titanium upon single- and two-colour femtosecond double-pulse irradiation, Opt. Express 23, 25959-25971 (2015), https://doi.org/10.1364 OE.23.025959

[18]M. Gedvilas, J. Mikšys, and G. Račiukaitis, Flexible periodical micro- and nano-structuring of a stainless steel surface using dual-wavelength double-pulse picosecond laser irradiation, RSC Adv. 5, 75075-75080 (2015), https://dx.doi. org/10.1039/c5ra14210e

[19]S. Höhm, M. Herzlieb, A. Rosenfeld, J. Krüger, and J. Bonse, Femtosecond laser-induced periodic surface structures on silicon upon polarisation controlled two-colour double-pulse irradiation, Opt. Express 23, 61 (2015), https://doi. org/10.1364/OE.23.000061

[20]S. Höhm, M. Herzlieb, A. Rosenfeld, J. Krüger, and J. Bonse, Laser-induced periodic surface structures on fused silica upon cross-polarised two-colour double-fs-pulse irradiation, Appl. Surf. Sci. 336, 39-42 (2015), https://doi. org/10.1016/j.apsusc.2014.09.101

[21]S. Höhm, M. Herzlieb, A. Rosenfeld, J. Krüger, and J. Bonse, Dynamics of the formation of laserinduced periodic surface structures (LIPSS) upon femtosecond two-colour double-pulse irradiation of metals, semiconductors, and dielectrics, Appl. Surf. Sci. 374, 331-338 (2016), https://doi. org/10.1016/j.apsusc.2015.12.129

[22]P. Demange, R.A. Negres, A.M. Rubenchik, H.B. Radousky, M.D. Feit, and S.G. Demos, Understanding and predicting the damage performance of $\mathrm{KD}_{x} \mathrm{H}_{2-x} \mathrm{PO}_{4}$ crystals under simultaneous exposure to $532-$ and $355-\mathrm{nm}$ pulses, Appl. Phys. Lett. 89, 181922 (2006), https://doi. org/10.1063/1.2378484

[23]L. Yan, C. Wei, Y. Zhao, K. Yi, and J. Shao, Multiple wavelength laser induced damage of multilayer beam splitters, Proc. SPIE 8530, 1-16 (2012), https://doi.org/10.1117/12.977254

[24]L. Yan, C. Wei, D. Li, K. Yi, and Z. Fan, Dualwavelength investigation of laser-induced damage in multilayer mirrors at 532 and $1064 \mathrm{~nm}$, Opt. Commun. 285, 2889-2896 (2012), https:// doi.org/10.1016/j.optcom.2012.02.028

[25] L. Lamaignere, S. Reyne, M. Loiseau, J.-C. Poncetta, and H. Bercegol, Effects of wavelengths combination on initiation and growth of laser-induced surface damage in $\mathrm{SiO}_{2}$, Proc. SPIE 6720, 67200F (2007), https://doi.org/10.1117/12.753057

[26]M. Mrohs, L. Jensen, S. Günster, T. Alig, and D. Ristau, Dual wavelength laser-induced damage threshold measurements of alumina/silica and hafnia/silica ultraviolet antireflective coatings, Appl. Opt. 55, 104-109 (2016), https://doi. org/10.1364/AO.55.000104

[27]S. Guizard, S. Klimentov, A. Mouskeftaras, N. Fedorov, G. Geoffroy, and G. Vilmart, Ultrafast breakdown of dielectrics: Energy absorption mechanisms investigated by double pulse experiments, Appl. Surf. Sci. 336, 206-211 (2015), https://doi.org/10.1016/j.apsusc.2014.11.036

[28]R.C.R. Santos, E. Longhinotti, V.N. Freire, R.B. Reimberg, and E.W.S. Caetano, Elucidating the high- $k$ insulator $\alpha-\mathrm{Al}_{2} \mathrm{O}_{3}$ direct/indirect energy band gap type through density functional theory computations, Chem. Phys. Lett., 637, 172-176 (2015), https://doi.org/10.1016/j. cplett.2015.08.004

[29]M. Liu and H.K. Kim, Strain-induced channel waveguiding in bulk sapphire substrates, 
Appl. Phys. Lett. 79, 2693 (2001), https://doi. org/10.1063/1.1413221

[30]R.H. French, R.L. Coble, R.V. Kasowski, and F.S. Ohuchia, Vacuum ultraviolet, photoemission and theoretical studies of the electronic structure of $\mathrm{Al}_{2} \mathrm{O}_{3}$ up to $1000^{\circ} \mathrm{C}$, Physica $\mathrm{B}+\mathrm{C} \mathbf{1 5 0}(1-2)$, 47-49 (1988), https://doi.org/10.1016/03784363(88)90104-0

[31]G.O. Williams and M. Fajardo, Densityfunctional-theory calculations of the optical properties of $\mathrm{Al}_{2} \mathrm{O}_{3}$ : From solid-state to warm dense matter conditions, High Energ. Dens. Phys. 33, 100718 (2019), https://doi.org/10.1016/j. hedp.2019.100718

[32]F. Ohuchi and Q. Zhong, Electronic structure of metal-ceramic interfaces, ISIJ Int. 30(12), 10591065 (1990), https://doi.org/10.2355/isijinternational.30.1059

[33]M. Gedvilas, J. Mikšys, J. Berzinš, V. Stankevič, and G. Račiukaitis, Multi-photon absorption enhancement by dual-wavelength double-pulse laser irradiation for efficient dicing of sapphire wafers, Sci. Rep. 7, 5218 (2017), https://doi. org/10.1038/s41598-017-05548-x

[34] M.J. Liu, Simple technique for measurements of pulsed Gaussian-beam spot sizes, Opt. Lett. 7, 196198 (1982), https://doi.org/10.1364/OL.7.000196

[35]B. Chimier, O. Uteza, N. Sanner, M. Sentis, T. Itina, P. Lassonde, F. Legare, F. Vidal, and J.C. Kieffer, Damage and ablation thresholds of fused-silica in femtosecond regime, Phys. Rev. B 84, 094104 (2011), https://doi.org/10.1103 PhysRevB.84.094104

[36]F. Wang, J. Shan, E. Knoesel, M. Bonn, and T.F. Heinz, Electronic charge transport in sapphire studied by optical-pump/THz-probe spectroscopy, Proc. SPIE 5352, 216-221 (2004), https://doi.org/10.1117/12.532505

[37]B.S. Wherrett, Scaling rules for multiphoton interband absorption in semiconductors, J. Opt. Soc. Am. B 1(1), 67-72 (1984), https://doi. org/10.1364/JOSAB.1.000067

[38]E. Arola, Theoretical studies on multiphoton absorption of ultrashort laser pulses in sapphire, IEEE J. Quantum Electron. 50(8), 1-12 (2014), https://doi.org/10.1109/JQE.2014.2328101
[39]F. Quéré, S. Guizard, P. Martin, G. Petite, O. Gobert, P. Meynadier, and M. Perdrix. Ultrafast carrier dynamics in laser-excited materials: sub-picosecond optical studies, Appl. Phys. B 68, 459-463 (1999), https://doi.org/10.1007 s003400050649

[40]L. Capuano, D. de Zeeuw, and G.R.B.E. Römer, Towards a numerical model of picosecond lasermaterial interaction in bulk sapphire, J. Laser Micro Nanoeng. 13(3), 166-177 (2018), https:// doi.org/10.2961/jlmn.2018.03.0005

[41]C. Karras, Z. Sun, D.N. Nguyen, L.A. Emmert, and W. Rudolph, The impact ionization coefficient in dielectric materials revisited, Proc. SPIE 8190, 819028 (2011), https://doi.org/10.1117/12.899267

[42]M. Giehler, H. Kostial, R. Hey, and H.T. Grahn, Effect of free-carrier absorption on the threshold current density of GaAs/(Al,Ga)As quantum-cascade lasers, J. Appl. Phys. 96, 4755-4761 (2004), https://doi.org/10.1063/1.1803635

[43]S. Guizard, N. Fedorov, A. Mouskeftaras, and S. Klimentov, Femtosecond laser ablation of dielectrics: experimental studies of fundamental processes, AIP Conf. Proc. 1278, 336 (2010), https://doi.org/10.1063/1.3507119

[44]I. Chowdhury, A. Wu, X. Xu, and A. Weiner, Ultra-fast laser absorption and ablation dynamics in wide-band-gap dielectrics, Appl. Phys. A 81, 1627-1632 (2005), https://doi.org/10.1007 800339-005-3326-x

[45]S. Wu, D. Wu, J. Xu, H. Wang, T. Makimura, K. Sugioka, and K. Midorikawa, Absorption mechanism of the second pulse in double-pulse femtosecond laser glass microwelding, Opt. Express 21, 24049-24059 (2013), https://doi. org/10.1364/OE.21.024049

[46] S.S. Mao, F. Quere, S. Guizard, X. Mao, R.E. Russo, G. Petite, and P. Martin, Dynamics of femtosecond laser interactions with dielectrics, Appl. Phys. A 79, 1695-1709 (2004), https://doi.org/10.1007 800339-004-2684-0

[47] M.L. Bortz, R.H. French, D.J. Jones, R.V. Kasowski, and F.S. Ohuchi, Temperature dependence of the electronic structure of oxides: $\mathrm{MgO}, \mathrm{MgAl}_{2} \mathrm{O}_{4}$ and $\mathrm{AI}_{2} \mathrm{O}_{3}$, Phys. Scr. 41, 537-541 (1990), https:// doi.org/10.1088/0031-8949/41/4/036 
[48]J.B. Varley, A. Janotti, C. Franchini, and C.G. Van de Walle, Role of self-trapping in luminescene and p-type conductivity of wide-bandgap oxides, Phys. Rev. B 85, 081109(R) (2012), https://doi.org/10.1103/PhysRevB.85.081109

[49] B. Namozov, M. Fominich, R. Zakharchenya, and V. Myurk, Structure of the self-trapped exciton luminescence in $\alpha-\mathrm{Al}_{2} \mathrm{O}_{3}$, Phys. Solid State 40, 837 (1998), https://doi.org/10.1134/1.1130416

[50]A.M. Stoneham, J. Gavartin, A.L. Shluger, A.V. Kimmel, D. Munoz Ramo, H.M. Rønnow, G. Aeppli, and C. Renner, Trapping, self-trapping and the polaron family, J. Phys. Condens. Matter 19, 255208 (2007), https://doi.org/10.1088/0953$8984 / 19 / 25 / 255208$

[51]S. Lederer, S. Akhmadaliev, P. Forck, E. Gütlich, A. Lieberwirth, and W. Ensinger, Thermal annealing behavior of $\alpha-\mathrm{Al}_{2} \mathrm{O}_{3}$ scintillation screens, Nucl. Instrum. Methods Phys. Res. B 365, 548-552 (2015), https://doi.org/10.1016/j. nimb.2015.08.024

[52]T. Watcharatharapong, J.T. Thienprasert, and S. Limpijumnong, Theoretical study of optical properties of native point defects in $\alpha-\mathrm{Al}_{2} \mathrm{O}_{3}$, Integr. Ferroelectr. 156(1), 79-85 (2014), https:// doi.org/10.1080/10584587.2014.906290

[53]R. Baltramiejunas, V.D. Ryzhikov, V. Gavryushin, A. Kazlauskas, G. Raciukaitis, V.I. Silin, D. Juodzbalis, and V. Stepankevicius, Luminescent and non-linear spectroscopy of recombination centers in isovalent doped ZnSe:Te crystals, J. Lumin. 52, 71-81 (1992), https://doi.org/10.1016/00222313(92)90234-Z

[54]R. Baltrameyunas, V. Gavryushin, G. Rachyukaitis, V. Ryzhikov, A. Kazlauskas, and V. Kubertavichyus, Spectroscopy of deep centers in ZnSe:Te single crystals based on laser modulation of two-stage absorption, Sov. Phys. Semicond. 22(7), 738-743 (1988).

[55]C.B. Samantaray, H. Sim, and H. Hwang, Firstprinciples study of electronic structure and electron-energy-loss-spectroscopy (EELS) of transition-metal aluminates as high- $k$ gate dielectrics, Appl. Surf. Sci. 242, 121-128 (2005), https://doi. org/10.1016/j.apsusc.2004.08.004
[56]J. Dienes, D.O. Welch, C.R. Fischer, R.D. Hatcher, O. Lazareth, and M. Samberg, Shell-model calculation of some point-defect properties in $\alpha-\mathrm{Al}_{2} \mathrm{O}_{3}$, Phys. Rev. B 11(8), 3060-3070 (1975), https://doi. org/10.1103/PhysRevB.11.3060

[57]V.A. Pustovarov, V.Sh. Aliev, T.V. Perevalov, V.A. Gritsenko, and A.P. Eliseev, Electronic structure of an oxygen vacancy in $\mathrm{Al}_{2} \mathrm{O}_{3}$ from the results of $\mathrm{Ab}$ Initio quantum-chemical calculations and photoluminescence experiments, J. Exp. Theor. Phys. 111(6), 989-995 (2010), https://doi. org/10.1134/S1063776110120113

[58]O.A. Dicks, J. Cottom, A.L. Shluger, and V.V. Afanasev, The origin of negative charging in amorphous $\mathrm{Al}_{2} \mathrm{O}_{3}$ films: the role of native defects, Nanotechnology 30, 205201 (2019), https://doi. org/10.1088/1361-6528/ab0450

[59]G. Wang, H. Zuo, M. Zhang, X. He, H. Han, C. Xu, J. Yang, and B. Grigoryan, The spectra and color centers of large sapphire crystal, Rare Metal Mater. Engineer. 36, 457-460 (2007).

[60]D.V. Ananchenko, S.V. Nikiforov, G.R. Ramazanova, R.I. Batalov, R.M. Bayazitov, and H.A. Novikov, Luminescence of sapphire single crystals irradiated with high-power ion beams, J. Phys. Conf. Ser. 1115, 052027 (2018), https://doi. org/10.1088/1742-6596/1115/5/052027

[61]B.D. Evans and M. Stapelbroek, Optical properties of the $F^{+}$center in crystalline $\mathrm{Al}_{2} \mathrm{O}_{3}$, Phys. Rev. B 18, 7089-7098 (1978), https://doi.org/10.1103/ PhysRevB.18.7089

[62] V.S. Kortov, V.A. Pustovarov, S.V. Zvonarev, and T.V. Shtang, Luminescence and radiation-induced color centers in anion-defective alumina crystals after high-dose irradiation, Radiat. Meas. 90, 90-93 (2016), https://doi.org/10.1016/j.radmeas.2016.01.010

[63] M. Izerrouken and T. Benyahia, Absorption and photoluminescence study of $\mathrm{Al}_{2} \mathrm{O}_{3}$ single crystal irradiated with fast neutrons, Nucl. Instrum. Methods Phys. Res. B 268, 2987-2990 (2010), https://doi.org/10.1016/j.nimb.2010.05.024

[64]E. Shablonin, A.I. Popov, G. Prieditis, E. Vasil'chenko, and A. Lushchik, Thermal annealing and transformation of dimer $F$ centers in 
neutron-irradiated $\mathrm{Al}_{2} \mathrm{O}_{3}$ single crystals, J. swift heavy ion irradiation, Radiat. Meas. 36(1-

Nucl. Mater. 543, 152600 (2021), https://doi. 6), 723-727 (2003), https://doi.org/10.1016/ org/10.1016/j.jnucmat.2020.152600 \$1350-4487(03)00234-8

[65]T. Mohanty, N.C. Mishra, F. Singh, S.V. Bhat, and

D. Kanjila, Color center formation in sapphire by

\title{
SAFYRO KRISTALO SUŽADINIMAS INTENSYVIA DVIEJŲ SPALVŲ PIKOSEKUNDINIO LAZERIO SPINDULIUOTE
}

\author{
M. Gedvilas, V. Stankevič, G. Račiukaitis \\ Fiziniu ir technologijos mokslu centras, Vilnius, Lietuva
}

\begin{abstract}
Santrauka
Ultratrumpųjų impulsų lazeriai yra plačiai taikomi apdirbant skaidrias medžiagas. Kristalinis safyras yra viena plačiausiai naudojamų skaidrių medžiagų, tačiau dèl kietumo ji sunku apdirbti mechaniniais metodais. Paslèptasis lazerinis raižymas yra vienas iš perspektyviausių safyro padèklų perpjovimo būdų. Siekiant inicijuoti paslèptajj safyro raižymą, šiame darbe buvo naudojama dviejų impulsų dviejų bangos ilgių kombinuota pikosekundinio lazerio spinduliuotè. Panaudotas kolinearus dviejų pluoštų su 355 ir 1064 nm bangos ilgiais, 10 ps impulso trukme ir 0,1 ns velinimu tarp impulsuc kombinavimas. Kadangi abiejų pluoštų fotonų energija yra gerokai mažesnè nei draustinių energijų tarpas, buvo išanalizuoti ịvairūs daugiafotonio sužadinimo keliai.
\end{abstract}

Eksperimentiškai žymus, iki keturių kartų modifikacijos srities padidejimas buvo stebimas, kai infraraudonosios ir ultravioletinès spinduliuočių intensyvumas kito siaurame diapazone. Darbe išanalizuotas labiausiai tikètinas rezonansinis dvieju spalvų lazerio ir safyro kristalo sąveikos mechanizmas, dèl kurio pasiektas iki keturių kartų didesnis sužadinimas, apimantis safyro defektų energetinius lygmenis ir daugiafotonès sugerties kombinacijas. Remiantis ankstesne daugiafotoninès spektroskopijos patirtimi buvo išanalizuoti įvairūs elektronų sužadinimo intensyvia lazerio šviesa safyre modeliai. Parengti spalvinių centrų, dalyvaujančių dviejų pakopu daugiafotoninejje sugertyje safyre, apšvitinant jị intensyvia lazerio spinduliuote, energetiniai modeliai. 